THE ARGONNE RADIOLOGICAL

IMPACT PROGRAM (ARIP)

Part I. Carcinogenic Hazard from

Low-level, Low-rate Radiation

Norman A. Frigerio, Keith F. Eckerman, and Ralph S. Stowe

ARGONNE NATIONAL LABORATORY, ARGONNE, ILLINOIS

Prepared for the U.S. ATOMIC ENERGY COMMISSION under Contract W-31-109-Eng-38 


\section{DISCLAIMER}

This report was prepared as an account of work sponsored by an agency of the United States Government. Neither the United States Government nor any agency Thereof, nor any of their employees, makes any warranty, express or implied, or assumes any legal liability or responsibility for the accuracy, completeness, or usefulness of any information, apparatus, product, or process disclosed, or represents that its use would not infringe privately owned rights. Reference herein to any specific commercial product, process, or service by trade name, trademark, manufacturer, or otherwise does not necessarily constitute or imply its endorsement, recommendation, or favoring by the United States Government or any agency thereof. The views and opinions of authors expressed herein do not necessarily state or reflect those of the United States Government or any agency thereof. 


\section{DISCLAIMER}

Portions of this document may be illegible in electronic image products. Images are produced from the best available original document. 
The facilities of Argonne National Laboratory are owned by the United States Government. Under the terms of a contract (W-31-109-Eng-38) between the U. S. Atomic Energy Commission, Argonne Universities Association and The University of Chicago, the University employs the staff and operates the Laboratory in accordance with policies and programs formulated, approved and reviewed by the Association.

\section{MEMBERS OF ARGONNE UNIVERSITIES ASSOCIATION}

The University of Arizona

Carnegie-Mellon University

Case Western Reserve University

The University of Chicago

University of Cincinnati

Illinois Institute of Technology

University of Illinois

Indialla. University

Lowa State University

The University of Iowa
Kansas State University The University of Kansas Loyola University Marquette University Michigan State University The University of Michigan University of Minnesota University of Missouri Northwestern University University of Notre Dame
The Ohio State University

Ohio University

The Pennsylvania State University

Purdue University

Saint Louis University

Southern Illinois University

The University of Texas at Austin

Washington University

Wayne State University

The University of Wisconsin

\section{NOTICE}

This report was prepared as an account of work sponsored by the United States Government. Neither the United States nor the United States Atomic Energy Commission, nor any of their employees, nor any of their contractors, subcontractors, or their employees, makes any warranty, express or implied, or assumes any legal liability or responsibility for the accuracy, completeness or usefulness of any information, apparatus, product or process disclosed, or represents that its use would not infringe privately-owned rights.

Printed in the United States of America Available from

National Technical Information Service

U.S. Department of Commerce 5285 Port Royal Road

Springfield, Virginia 22151

Price: Printed Copy $\$ 4.00 ;$ Microfiche $\$ 1.45$ 


\section{ARGONNE NATIONAL LABORATORY \\ 9700 South Cass Avenue \\ Argonne, Illinois 60439}

THE ARGONNE RADIOLOGICAL IMPACT PROGRAM (ARIP)

Part I. Carcinogenic Hazard from Low-level, Low-rate Radiation

\section{by}

\section{Norman A. Frigerio, Keith F. Eckerman, and Ralph S. Stowe}

\section{Envi ronmental Statement Project}

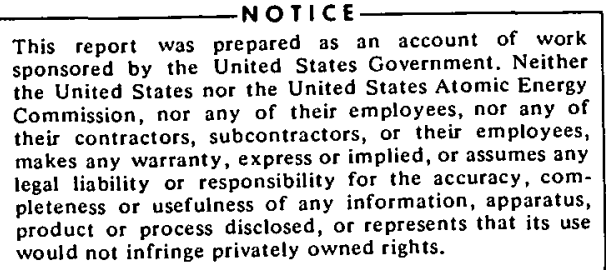

would not infringe privately owned rights.

September 1973 


\section{THIS PAGE \\ WAS INTENTIONALLY \\ LEFT BLANK}


TABLE OF CONTENTS

$\underline{\text { Page }}$

LIST OF VARIABLES . . . . . . . . . . . . . . . . . . . . 4

ABSTRACT . . . . . . . . . . . . . . . . . . . . 5

INTRODUCTION . . . . . . . . . . . . . . . . . . . . 5

THE PROBLEM . . . . . . . . . . . . . . . . . . . . . . . 7

LINEAR MODELS . . . . . . . . . . . . . . . . . . . . . 8

THE ADDITIVE MODEL . . . . . . . . . . . . . . . . . . . 10

ADDITIVE MODEL IN INFANCY . . . . . . . . . . . . . . . 16

THE MULTIPLICATIVE MODEL . . . . . . . . . . . . . . . . . 19

OTHER MODELS . . . . . . . . . . . . . . . . . . . . . . . 27

FUTURE MODELS . . . . . . . . . . . . . . . . . . . . 28

CONCLUSIONS . . . . . . . . . . . . . . . . . . . . . . 29

REFERENCES AND NOTES . . . . . . . . . . . . . . . . . 32

No.

LIST OF FIGURES

1: Malignant Mortality Rates for the U. S. White Population, 1950-1967, by. State and Natural Background . . . . . . . . . 20

\section{LIST OF TABLES}

No.

1. Observations of U. S. Cancer Mortalities vs. Radiogenic.

Expectation at Three Expectation Levels . . . . . . . . . . . 12

2. Minimum National Rates for Ten Malignancy Types . . . . . . . . 14

3. Cancer Mortality and Expectations, 0-9 Year Group . . . . . .. . 17

4. U. S. Low and High Background White Populations, 1950-1967 . . . 22

5. Characteristics of U. S. White Populations at Low and High Backgrounds . . . . . . . . . . . . . . . . . . 30 


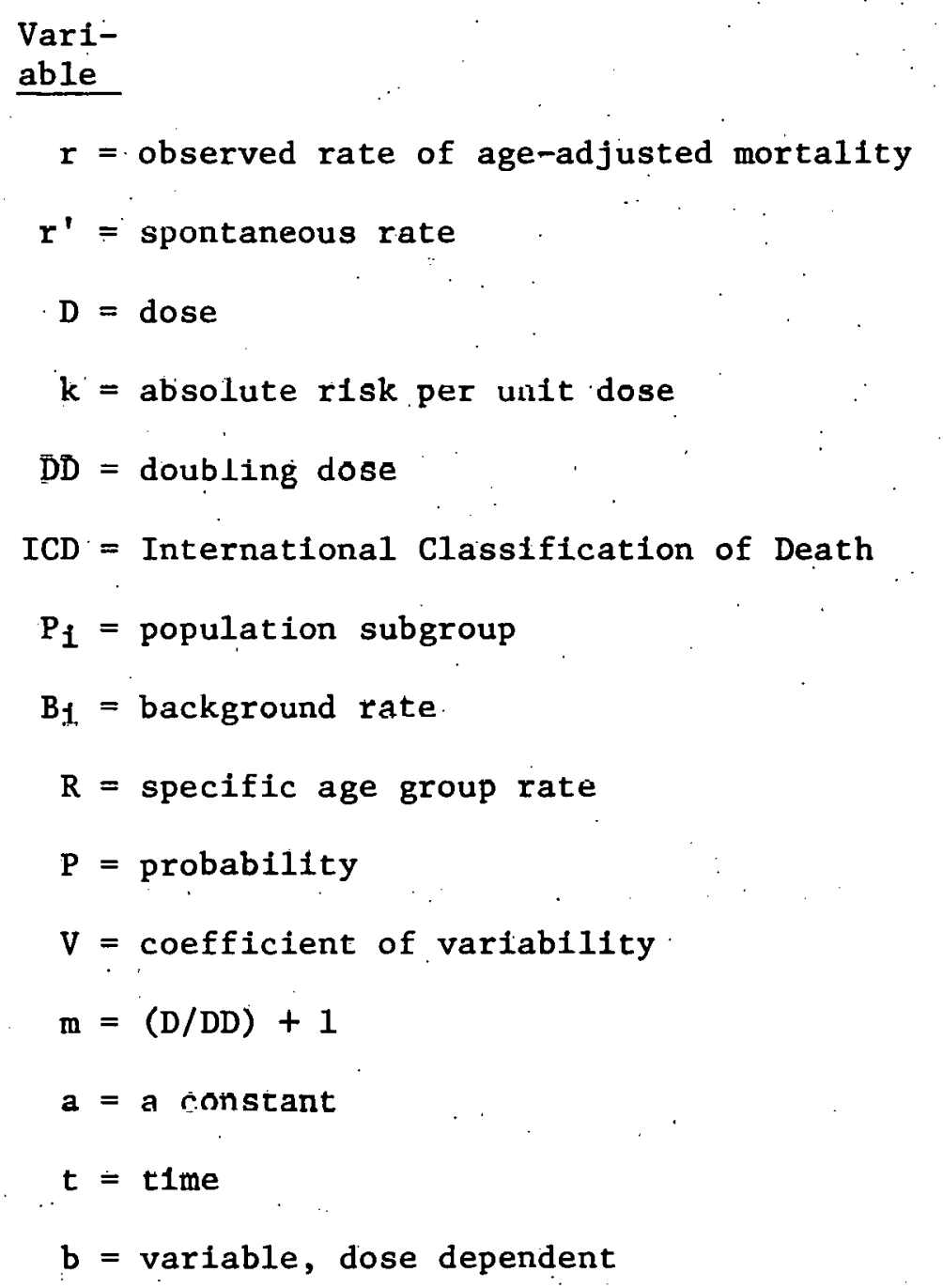




\title{
THE ARGONNE RADIOLOGICAL IMPACT PROGRAM (ARIP) \\ PART I. CARCINOGENIC HAZARD FROM LOW-LEVEL, LOW-RATE RADIATION
}

by

Norman A. Frigerio, Keith F. Eckerman; and Ralph S. Stowe

\begin{abstract}
The entire Argonne Radiological Impact Program is briefly. outlined, and part of the program dealing with radiation hazards from nuclear power plants is discussed in detail. Various models and predictions of carcinogenic hazard are examined and compared with actual experience in U. S. and foreign populations. AII of the models predict a significant increment in malignant mortality with increasing background. Observation of the actual populations at risk shows not only no increment, but an actual decrement, so that these predictions are left quite without observational support. It is concluded that extrapolation of high-rate and usually high dose-level studies to low rates and low levels is probably invalid, and that radiation at such levels and rates does not constitute an environmental carcinogen of significance.
\end{abstract}

\section{INTRODUCTION}

In late 1971 the Environmental Statement Project was formed at Argonne National Laboratory to aid the U. S. Atomic Energy Commission in the preparation of environmental statements for the nuclear facilities being licensed by the Commission. Since methodology for assessing the impact of such facilities was in its infancy, it was necessary for us to develop methods and programs adequate to the task. For questions of radiological impact this eventually tonk. the form of a series of studies, reporte, rccommcnda tions and computer programs which, taken together, formed the Argonne Radiological Impact Program (ARIP). This report, ARIP I, concerns itself with evaluation of the carcinogenic hazard that might be associated with the radiation and radioactivity from nuclear facilities. Future ARIP reports will address other parts of the program, e.g.: the determination of optimum sites for nuclear facilites (II); evaluation of the doses received by man and other biota from the releases of nuclear facilities (III); storage and access of available data on radiation and radioactivity levels in the U. S. (IV); e.tr.

A recent report has summarized what is known of the genetic and somatic hazards of radiation. ${ }^{32}$ The principal somatic hazard was found to be carcinogenesis, and genetic and somatic hazards were found to be of about the same severity per unit dose. Our evaluations of nuclear power reactors, present and proposed, revealed that the major fraction of the dose received by man and other biota was somatic rather than genetic. The spectrum of 
radionuclides emitted by a power plant, in conjunction with the pathways by which they reached man and other biota, almost invariably resulted in critical organ doses about an order of magnitude higher than the genetically significant doses received from the same source. The inexorable arithmetic of carcinogenesis renders the critical organ dose truly critical to the survival of the individual irradiated. While the probability of cancer in any organ is proportional only to the dose to that organ, the survival of the individual is largely independent of which organ becomes cancerous. At the present state of the art in cancer therapy, the survival of the individual is seriously threatened by cancer in any organ. Thus, radiation hazard from nuclear plants, small as it may be, is defined by the critical organ doses received. Thus such concepts as "whole body" dose are germane to the question of hazard only at a secondary level relative to critical organ doses.

So far as is known. the radiation and radioactivity from a nuclear power plant is not uniquely hazardous and that, so long as doses are expressed in common units (i.e. rem), the hazard is independent of source. ${ }^{32}$ In terms of both dose rate and dose level, radiation hazard from nuclear plants most closely resembles background radiation. Thus, we opined that a study of carcinogenesis occasioned by the radiation background would constitute the most pertinent test of the potential carcinogenicity radiation and radioactivity from nuclear power plants. 
In recent years, the hypothesis has been advanced that a significant fraction of human cancer mortality may be due to the human radiation background. $1-3,13,31-33$ For a normalized irradiation of $170 \mathrm{mi} 11$ irem/yr, these authors have estimated U. S. cancer mortality excesses of about 3,000 to 100,000 per year, i.e., about $1 \%$ to $30 \%$ of current experience. Since the identification of so important an etilogic factor would be an event of major significance in the field of cancer epidemiology, we addressed ourselves to the examination ${ }^{24}$ of the degree to which these hypotheses could be justified from current vital statistics and from the known variations in the radiation background.

This examination occupied a fair span of time, during which the mists of our comprehension cleared only slowly. 55 We began with vital statistics, recognizing that they form only a small part of the epidemiologic method, but intending to go on when they wore thin. Much to our surprise they continued to lead us on until, at the end, we had hardly applied anything else. We beg the reader's indulgency, therefore, if what we present is less in logical than in chronological order. We hope thus to indicate how it was possible for us to begin with the presumption that background radiation must be carcinogenic only to be forced, after something very much like the classic Drunkard's Walk, 19 to conclude that it is not. 


\section{LINEAR MODELS -- THE GIVENS}

The estimates given above all depend on linear extrapolation of data obtained at high dose-rates, and generally high doses, to the low-rate, low-dose condition of the natural background. The linear models involved have taken two forms; the additive, or absolute-risk, mode1, and the multiplicative, or relative-risk, model. Formally, these may be written as: 22

$$
\begin{array}{ll}
\mathbf{r}=\mathbf{r}^{\prime}+\mathrm{kD} & \text { additive, } \\
\mathbf{r}=\mathbf{r}^{\prime}+\mathbf{r}^{\prime}(\mathrm{D} / \mathrm{DD}) & \text { multiplicative. }
\end{array}
$$

Here $r$ is the observed rate of age-adjusted mortality, $r$ ' the "spontaneous" or radiation-independent rate, and $D$ the dose. $k$ is the absolute risk per unit dose, and DD the so-called "doubling dose," a measure of relative risk.

These two models differ in the role assigncd radiation 36 a carcinogen. The additive model treats radiation as a complete carcinogen, sufficient unto itself, and with no need for co-carcinogens. The multiplicative model treats radiation as a pure co-carcinogen, amplifying whatever malignancy already exists; but not necessarily adding any on its own.

The estimates cited have all made use of five "generalizarions," althuugh these have been made most explicit only in the most recent reports. 2, 32 Following Gofman and Tamplin, ${ }^{2}$ we have termed these "generalizations" rather than "assumptions" since they are based on an impressive assemblage of human and animal data as we 11 as an extensive collection of theoretical discussions. Properly speaking, the "assumption" at issue was whether this data, involving small, selected groups at high doses and/or high dose-rates, could be linearly extrapolated to the U. S. population as a whole.

In the estimatco procented to date, the following generalizations have been employed: $1-3,13,31-33$

(1) Radiation is a pan- to polycarcinogen, i.e. a1l/many sites are subject to radiation carcinogenesis, and in about the same measure;

(2) Radiation sensitivity is independent of dose rate, but drops sharply during the first three decades of life, so that only the background dose received during the first 30 years is considered in estimating population risks over all ages. Fur a normalized background irradiation of 170 mrem/yr, this amnints to a total dose, $D$, of ahnut. 5.1 rem;

(3) Estimates of total risk can be made assuming an age-averaged sensitivity over the entire population. For the additive model, estimates of $k$ have ranged from 0.3 to 9.0 death 3 per year per 100,000 population per rem. For the multiplicative model, estimates of doubling dose have ranged from about 50 to 500 rem. These ranges correspond, rough $1 y$, to from $1 \%$ to $30 \%$ of the current U. S. malignant mortality of about $320,000 / \mathrm{yr}$. While many workers have used only a single value for sensitivity, others have utilized specific functions for generalization (2), and integrated these over 
age to provide the most explicit estimates; ${ }^{2,32}$

(4) Aside from age, populations have been treated as equivalent -regardless of "race, creed or color," so to speak. While this generalization has seldom been made explicit, it has always been implicit, as witness the extrapolation of data from Japanese bomb victims, uranium miners, spondylitics, infants radiographed in utero malignancy-bearing patients and the like, to the U. S. population as a whole; and

(5) Latent periods for the initial appearance of radiogenic malignant mortality range from a few years for infants to as much as 30 years for adults. The bulk of the values used have been $\leqq 5$ years for infants and $\leqq 20$ years for adults.

In testing the two forms of the linear model, we utilized these generalizations as they stood. Natural background for each state were taken from Minx, Schleien, et $a{ }^{6}{ }^{6}$, and applied equally to both sexes and all races within the state. A man-made background (medical, fallout, nuclear devices, etc.) of $40 \mathrm{millirem} / \mathrm{yr}$ was added to the natural background: While this is admittedly lower than the 95 millirem given for $1972^{6}$ or the 45-61 given for the 1960 's, 12 it was chosen as a reasonable, conservative average for. the period 1950-1968.32 It makes some allowances for the presence in the population of groups whose medical exposure is probably low, and adds nicely to the U. S. average natural background ${ }^{6}$ of $130 \mathrm{mrem} / \mathrm{yr}$ to give the $170 \mathrm{mrem} / \mathrm{yr}$ which has so often been used as the basis of estimates. For some tests we needed a distribution function for radiogenic malignant mortality. We could find nothing explicit on this in the presentations. However, from the Poisson nature of radiation itself and the linear form of the model, we inferred Poisson statistics for radiogenic components of malignant mortality.

The major disagreements among the various authors seem to have centered on (1.) and (3.), as well as on the length of the plateau to be anticipated once the latent period had been exceeded. In order to arrange tests of all the variations, therefore, we added the following operational provisos:

(1a.) We would begin with the assumption of pancarcinogenesis. But we would also arrange the tests so that, if this were not the case, sites would be eliminated until only those corresponding to polycarcinogenesis would be left.

(3a.) We would begin with a high sensitivity and apportion it equally among the various sites. But we would also decrease this value progressively, toward zero, so as to encompass predictions made on the basis of various sensitivities and plateaus. 
THE ADDITIVE MODEL

From generalizations ( 1 ) and (4) and the form of the additive equation; no general population may show a rate, $r$, of zero: Even if $r^{\prime}=0, r$ will be equal to $\mathrm{kD}$. Of course, an observation of $r=0$ may be made if the statistics of sampling are such that $\mathrm{kD}$ cannot be distinguished from zero. Similarly, if other carcinogens are present, 9 or the population shows a heterogeneity of sensitivity, $34 \mathrm{r}$ may be greater than $\mathrm{kD}$. In such cases there is simply no test. But $r$ should never be lower than $\mathrm{kD}$ in this mode $1 .{ }^{9}$

Following the methodology of Higginson, 9 we attempted to determine if there were any subpopulations in the U. S. that violated this stricture, i.e., for which $r$ was less than $k D$.

We were fortunate to have before us Burbank's 5 outstanding recent compadium of U. S. cancer mortality for the 18-year period 1950-196\%. Our analyses were performed on his Static Geographic Tables, using his ICD types, age-adjusted death rates, population bases, etc. These group the U. S. population into 200 groups for each ICD (International Classification of Death) ${ }^{5}$ type, i.e., 50 states, two sexes, and two races (white and non-white). ICD types 171-179 concern sites specific to only one sex, and were thus represented by 100 groups each. For details not available in Burbank, we utilized the available U.S. Statistics for $1950-1968,27,28$ but the same methodology. 5

These groups are listed by 55 specific ICD malignancy (Mn) types, plus one "all other" category, -- Burbank No. 65. The latter includes ICD malignancy types Mn 156, 165, 195, 198, and 199.

From generalizations $(1,1 a)$ there must be roughly equal distribution of radiogenic malignant mortalities among the $56 \mathrm{Mn}$ Lypes. At $\mathrm{k}=3.2$ and $D=5.1$, this would lead to an excess national mortality of about $33,600 / y r$, i.e., about $10 \%$ of current experience. Spread over $56 \mathrm{Mn}$ types, this corresponds to $r=0.3$ per $\mathrm{Mn}$ type, i.e., an expectation of about 54 radiogenic deaths per million population per Mn type for the 18-year period of observation. In order to run the gamut of proposed expectalions, we firot identified populations presenting at rates below 0.3 and 0.03 , discriminated by sex, race, Mn type, and state of residence. The hope was that we would thus bracket some $r$ at which the linear additive model would be casily tenable.

Observed mortalities were derived from Burbank ${ }^{5}$ or obtained from the U. S. Vital Statistics.27,28 " $t$ " values were taken (expectation-observation)/ (standard error) in the usual fashion.11,18 Radiogenic expectation was taken as:

$$
\text { expl. }=\underset{i}{=} \sum_{i}(18)(k / 56)(30) B_{i} P_{1}
$$

where each population subgroup, $P_{i}$, had been exposed to radiation at its particular background rate, $B_{i}$, for the first 30 years of life and observed over 18 years for the designated malignancy at a sensitivity of $(k / 56)$ per Mn type. 
These expectations are given in the first colum of each $r$ group. Although, in cancer epidemiology, one would not usually consider expectations less than 5 or so, 11 . much less express them as decimals, this has been the practice in radiation carcinogenesis studies. 13,32 . Thus, we have allowed this practice at $\mathbf{r}=0.3$ or 0.03 . At $\mathbf{r}=0.003$ we have used only a plus sign $(+)$ to indicate that the value for $t$ is mathematically real but less than 1 .

Population of each cohort presenting at $\leq r$ is also given (in thousands) as well as the weighted average dose level characterizing the cohort. At the bottom of the table we have summarized the number of malignancy types at various $t$ levels, signaling those of observations less than expectation by the device of a "positive" $t$, and the converse by a "negative" $t$. The latter have also been signaled by dashes in the body of the table. In each case, the total of types is 56 .

With so many Mn sites violating the requirements of the model, even as judged simply by the normal " $t$ ". test, we had to admit that it was extraordinarily improbable, at least at these levels. So, we continued dropping our search value for $r$ until, at 0.006 , all of the observations went to zero except for those three stalwarts, ICD 151, 153 and 171 . Since we thought we might have something here, we did our estimations on the basis of $r=0.003$, the mid-value of the interval, rather than 0.006 , its upper bound.

In this range level, the normal " $t$ " test becomes awkward.11,18 Thus, we resorted to the much more powerful, albeit lengthy and expensive, Monte Carlo method.19 Briefly the population of the U. S. was subjected to a random "rain" of radiocarcinogenci deaths at $r=0.003$ for 10018 -year periods, and the results of each period analyzed as above. Where the $r=0.003$ colum of $\mathrm{Table} 1$ shows zero observed deaths for 53 tumor types we found a range of 11-33. By the 35th trial, a mean of $20 \pm 2$ was reached, and this held to the end of trials. Ergo, not only is the null hypothesis $(r=0.003$ ) improbable, but the Monte Carlo results suggest that a level of rough $1 \mathrm{y} 0.003 / 20$ would be needed to reach even a $63 \%$ confidence 1 eve 1 . This corresponds to about 16 deaths/yr per $200,000,000$ population, or about $0.005 \%$ of current U. S. mortality. Since the same pattern of zero observations had been found at all levels of $\mathrm{r}$ below 0.006 , where the Monte Carlo expectation was about 41 , a null hypothesis $(r=0.006)$ was comensurately less probable.

Now, the observation that "large," geographically contiguous populations exist in which malignant mortality rates are quite low is hardly nove1.9,26,43 But, by making this sort of observation explicit: and more-or-1ess quantitative, it is more readily seen how this phenomenon places upper bounds on the involvement of background radiation in carcinogenesis. If there is a surprise, it is that the upper bound is as low as it is, at least in this otherwise persuasive mode1.

In any case the model certainly seemed untenable at any level much greater than $r=0.003 / 20=1.5 \times 10^{-4}$, at least as its authors originally presented it. In theory, we thought it might be saved by abandoning generalization (1) and confining higher expectations to 10 of the 56 types, even though these 10 corresponded poorly to those for which human radiocarcinogenesis had been shown. ${ }^{32}$ In practice, though, even this turned out 
Table 1 Observations of U. S. Zancer Mortalit_es vB. Radiogenic Expectation at Three Expectation Leve 18

\begin{tabular}{|c|c|c|c|c|c|c|c|c|c|c|c|c|c|c|c|}
\hline \multirow{2}{*}{$\begin{array}{l}\text { Mallemancy } \\
\text { type, ICI } \\
\text { No.. } \\
\end{array}$} & \multicolumn{5}{|c|}{$x=0.3$} & \multicolumn{5}{|c|}{$r=0.03$} & \multicolumn{5}{|c|}{$r=0.003$} \\
\hline & expt. & c.bs. & $t$ & $\begin{array}{l}\text { pop., } \\
\text { thous. }\end{array}$ & $\begin{array}{c}\text { Dose, } \\
\text { nxem/yx }\end{array}$ & expt. & obs. & $t$ & $\begin{array}{l}\text { poip., } \\
\text { thous. }\end{array}$ & $\begin{array}{c}\text { Dose, } \\
\text { mrem/yx }\end{array}$ & expt. & 056. & $t^{i}$ & $\begin{array}{l}\text { Pop., } \\
\text { thous. }\end{array}$ & $\begin{array}{l}\text { Dose, } \\
\text { mrem/yx }\end{array}$ \\
\hline 140 & $6 \pi 4$ & $=930$ & 58.3 & 129,259 & 170 & 350.8 & 242 & 5.8 & 66,150 & 173 & 2.5 & $J$ & 1.5 & 4404 & 182 \\
\hline 141 & 1433 & $=257$ & 4.8 & 26,213 & 279 & 1.4 & 0 & 1.2 & 218 & 207 & 0.14 & j & + & 218 & 207 \\
\hline 142 & 4908 & 3679 & 17.5 & 93,355 & 172 & 3.4 & 0 & 1.8 & 586 & 188 & 0.34 & 0 & + & 586 & 188 \\
\hline 143 & $6 \in 31$ & 2514 & 50.6 & $\pm 25,445$ & 173 & 83.8 & 12 & 2.4 & 4,175 & 186 & 1 & 0 & 1.0 & .1536 & 196 \\
\hline 144 & 3405 & 2436 & 16.6 & 63,850 & 174 & 2.0 & 0 & 1.4 & 324 & 204 & 0.20 & o & - & 324 & 204 \\
\hline 145 & $5 \div 48$ & 3059 & 46.8 & $=04,251$ & 174 & 14.5 & 3 & 3.0 & 2,394 & 198 & 1 & 0 & 1.0 & 1525 & 198 \\
\hline 146 & 5637 & $3658^{\circ}$ & 39.7 & $=06,579$ & 173 & 1.9 & 0 & 1.4 & 313 & 198 & 0.19 & 0 & + & $3=3$ & 198 \\
\hline 147 & 7093 & 3392 & 55.8 & $-34,277$ & 173 & 124.4 & 85 & 3.5 & 22,099 & 184 & 2 & 0 & 1.4 & 3173 & 192 \\
\hline 143 & 3477 & $3 \sqrt{43}$ & 17.5 & 65,090 & 175 & 2.9 & 0 & 1.7 & 501 & 191 & 0.29 & 0 & + & 501 & 191 \\
\hline 150 & 33 & 21. & 2.1 & 488 & 220 & 0.3 & 0 & 0.5 & 50 & 213 & 0.03 & .0 & + & .50 & 218 \\
\hline 151 & $\therefore$ & $\because$ & - & $\ldots$ & - & - &.- & - & -- & -- & - & - & - & $\because$ & $\because$ \\
\hline 152 & 1103 & 943 & 4.8 & 21,056 & 171. & 1.6 & 0 & 1.3 & 249 & 207 & 0.16 & 0 &. & 249 & 207 \\
\hline 153 & $\cdots$ & -- & - & -- & $\because$ & - & -- & - & $\cdots$ & $\because$ & - & - & - & $\therefore$ & $\because$ \\
\hline 154 & 1 & $a$ & 1.0 & 11. & 185 & 0.1 & 0 & 0.3 & 11 & 185 & 0.01 & 0 & + & 11 & 135 \\
\hline 155 & 0 & c & 0.0 & 4 & 170 & 0 & 0 & 0.0 & 4 & 170 & 0.00 & 0 & 0 & 4 & 170 \\
\hline 157 & 0 & c & 0.0 & 7 & 170 & 0 & 0 & 0.0 & $\mathrm{~T}$ & 170 & 0.00 & 0 & 0 & 7 & 170 \\
\hline 158 & 535 & $43 i$ & 4.2 & 9,709 & 180 & 1.8 & 0 & 1.3 & 335 & 180 & 0.18 & 0 & + & 335 & 180 \\
\hline 159 & 768 & 567 & 7.3 & 13,642 & 184 & 0.7 & 0 & 0.8 & 131 & 132 & 0.07 & 0 & + & 131 & 182 \\
\hline 160 & 4436 & 3496 & 14.9 & 85,627 & $i 7$ & 1.5 & 0 & 1.2 & 265 & 180 & 0.15 & 0 & + & 265 & 180 \\
\hline 161 & 3753 & $.280 \epsilon$ & 15.5 & 70,496 & 172 & 1.2 & 0 & 1.1 & 203 & 194 & 0.12 & 0 & + & 208 & 194 \\
\hline 162 & 1 & $c$ & 1.0 & 13 & 222 & 0.1 & 0 & 0.3 & 13 & 222 & 0.01 & 0 & + & 13 & 222 \\
\hline 163 & 0 & c & 0.0 & 2 & $17 \mathrm{C}$ & 0 & 0 & 0.0 & 2 & 170 & 0.00 & 0 & 0 & 2 & 170 \\
\hline 164 & 8273 & 4576 & 4.1 & 157,332 & $17 \%$ & 14.1 & 4 & 2.7 & 2483 & 186 & 0.78 & 0 & + & 1473 & 173 \\
\hline 170 & 3116 & $260 \mathrm{~L}$ & 9.2 & 59,719 & 17 & 1.3 & 0 & 1.1 & 232 & 179 & 0.13 & 0 & + & 238 & 179 \\
\hline 17 & -- & -- & - & - & $\because$ & - & -- & - & .- & $\because$ & - & - & - & $\therefore$ & $\therefore$ \\
\hline 172 & 2 & 0 & 1.4 & 39 & 206 & 0.2 & 0 & 0.4 & 30 & 209 & c.02 & 0 & + & 39 & 209 \\
\hline 173 & 4765 & 1254 & 50.9 & 90,819 & $17 \bar{E}$ & 14.8 & 7 & 2.0 & 2763 & 175 & 0.40 & 0 & + & 38 & 177 \\
\hline 174 & 0 & 0 & 0.0 & 5 & $27 \varepsilon$ & $\mathrm{c}$ & 0 & 0.0 & 3 & 272 & 0.00 & 0 & 0 & 5 & 272 \\
\hline 175 & 0 & 0 & 0.0 & 2 & 170 & 0 & 0 & 0.0 & 3 & 170 & 0.00 & 0 & 0 & 2 & 170 \\
\hline 176 & 6 & D) & 2.5 & 98 & 211 & 0.6 & 0 & 0.8 & 92 & 214 & 0.06 & 0 & + & 92 & 214 \\
\hline 177 & 0 & .) & 0.0 & 1 & 170 & 0 & 0 & 0.0 & 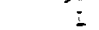 & 170 & 0.00 & 0 & 0 & 1 & 170 \\
\hline 178 & 293 & 232 & 3.6 & 5,601 & 17. & 0.6 & 0 & 0.8 & 105 & 189. & 0.06 & 0 & + & 105 & 189 \\
\hline 179 & 1483 & 135.7 & 3.3 & 23,817 & 168 & 1.0 & 0 & 1.0 & 170 & 193 & 0.10 & 0 & + & 170 & 193 \\
\hline 180 & 1 & $j$ & 1.0 & 13 & 208 & 0.1 & 0 & 0.3 & 19 & 208 & 0.01 & 0 & + & 18 & 208 \\
\hline 181 & 1 & j & 1.0 & 12 & 213 & 0.1 & 0 & 0.3 & 12 & 213 & 0.01 & 0 & + & 12 & 213 \\
\hline 190 & 454 & 385 & 3.2 & 3,836 & 168 & 2.5 & 0 & 1.6 & 414 & 199 & 0.25 & 0 & + & 414 & 199 \\
\hline 191. & 27 & 10 & 3.3 & 504 & 174 & 1.1 & 0 & 1.0 & 189 & 184 & 0.11 & 0 & + & 189 & 184 \\
\hline 192 & 9094 & 6143 & 30.9 & 173,507 & 17 & 9.3 & 2 & 2.4 & $17 C 2$ & 178 & 0.59 & 0 & + & 1054 & 183 \\
\hline 193 & 5 & 5 & 2.2 & 79 & $21 ;$ & 0.5 & 0 & 0.7 & 79 & 219 & 0.05 & 0 & + & 79 & 219 \\
\hline 194 & 550 & $5 C 3$ & 2.0 & 10,439 & 17 & 0.9 & 0 & 0.9 & 161 & 182 & 2.09 & $\theta$ & + & 161 & 182 \\
\hline 196 & 19 & 10 & 2.1 & 344 & 182 & 0.4 & 0. & 0.6 & 75 & 195 & 0.04 & 0 & + & 75 & 195 \\
\hline 197 & 47 & $\varepsilon 5$ & 3.2 & 875 & $1 \overline{5}$ & 0.3 & 0 & 0.9 & $1 \mathrm{L5}$ & 191 & 0.08 & 0 & + & 145 & 191 \\
\hline $200 . c$. & 307 & 211 & 5.5 & 5,704 & $1 \%$ & 1.2 & 0 & 1.1 & 183 & 207 & 0.12 & 0 & + & 183 & 207 \\
\hline 200.1 & 7 & 1 & 2.3 & 110 & 209 & 0.4 & 0 & 0.6 & $T a$ & 191 & 0.04 & 0 & + & 72 & $19 i$ \\
\hline $200 . \bar{\varepsilon}$ & 543 & 395 & 6.3 & 9,313 & $1 \varepsilon_{1}$ & 2.0 & 0 & 1.4 & 320 & 203 & 0.20 & 0 & + & 320 & 203 \\
\hline $201 . c$ & 9 & 3 & 2.0 & 150 & 205 & 0.2 & 0 & 0.4 & 27 & 220 & 0.02 & 0 & + & 27 & 220 \\
\hline 202.0 & 9411 & 1791 & 73.5 & 179,303 & $1 \pi$ & 158.5 & 85 & & 29.934 & 173 & 4 & 0 & 2.0 & 7928 & 175 \\
\hline 202. & $\begin{array}{l}9411 \\
2297\end{array}$ & 207 & $\begin{array}{l}10.3 \\
4.7\end{array}$ & $\begin{array}{r}119,303 \\
43,382\end{array}$ & $\begin{array}{l}1+2 \\
13\end{array}$ & $\begin{array}{l}120.3 \\
0.9\end{array}$ & 0 & 0.9 & $\begin{array}{r}29,934 \\
152\end{array}$ & & 0.09 & & + & 152 & 196 \\
\hline 205 & 9407 & 1301 & 83.6 & $\begin{array}{l}499,254 \\
1794\end{array}$ & $1=2$ & 372.0 & 268 & $\begin{array}{l}0.9 \\
5.4\end{array}$ & 70,943 & 171 & 2 & 0 & $1.4^{+}$ & 3685 & 181 \\
\hline 203 & 7 & 0 & 2.6 & 179.234 & 181 & $\begin{array}{r}52.0 \\
0.7\end{array}$ & $\begin{array}{l}260 \\
0\end{array}$ & $\begin{array}{l}3.4 \\
0.3\end{array}$ & $\begin{array}{l}0,943 \\
134\end{array}$ & $\begin{array}{l}111 \\
131\end{array}$ & 0.07 & 0 & $10.4+$ & 134 & 181 \\
\hline 204.0 & 18 & 10 & 1.9 & 330 & $1 ?+4$ & 0.5 & 0 & 0.7 & 37 & 190 & 0.05 & 0 & + & 87 & $\begin{array}{l}101 \\
190\end{array}$ \\
\hline 204.1 & 5 & 0 & 2.2 & 66 & 224 & 0.5 & 0 & 0.7 & 66 & 224 & 0.05 & 0 & $\begin{array}{l}+ \\
+\end{array}$ & 66 & 224 \\
\hline 204.3 & 1820 & 1350 & 11.0 & 34,132 & 174 & 3.2 & 0 & .1 & 541 & $\begin{array}{l}2<4 \\
191\end{array}$ & 0.32 & 0 & + & 541 & $\begin{array}{l}284 \\
191\end{array}$ \\
\hline 204.3 & 1020 & 1300 & 21.0 & 34,138 & 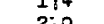 & 3.5 & 0 & 1.8 & 541 & 191 & 0.01 & 0 & + & 541 & 191 \\
\hline 204.3 & 1 & 0 & 1.0 & 14 & $2 \div 9$ & 0.1 & 0 & 0.3 & 14 & 219 & 0.13 & 0 & + & 14 & 219 \\
\hline 204.4 & 65 & 50 & 1.9 & 1,261 & 108 & 1.3 & 0 & 1.1 & 202 & 210 & 0.13 & 0 & + & 202 & 210 \\
\hline All Otzer & 0 & 0 & 0.0 & 1 & 170 & 0 & 0 & 0.0 & 1 & 170 & 0 & 0 & - & 1 & 170 \\
\hline Types at $t \geq$ & 2 & & 26 & & & $\begin{array}{l}5 \\
4\end{array}$ & & & & & & & $\begin{array}{l}0 \\
1\end{array}$ & & \\
\hline$" \quad \| \quad 2>t$ & 1 & & 21 & . & & 17 & & & & & & & 5 & & \\
\hline$" \quad " \quad 1>$ & 0 & & 7 & & & 26 & & & & & & . & 46 & & \\
\hline $11 \leq$ & & & 3 &. & & 4 & & & & & & & 4 & & \\
\hline
\end{tabular}


to be improbable when we examined this unholy decade by criteria other than $\mathbf{r}<\mathrm{kD}$ (vide infra).

As an aside, we might note that this sort of epidemiological approach possesses some peculiar advantages over less direct studies of radiation effects. For one thing it addresses itself directly to the population of interest, in this case that of the U. S. rather than to small, select populations of the war-torn (e.g., Hiroshima and Nagasaki), of the $i 11$ (e.g., those irradiated for spondylitis, tuberculosis, thyroiditis, malignancies, thymic disorders, etc.), of the young (e.g., irradiation for tinea), or of the occupationally stressed (e.g., uranium miners). It may be noted, for example, that even the smallest population groups in Table 1 are as large and usually much larger than these select irradiated groups.

Then, too, the time span of observation is large. Although we have dealt only with an 18 -year span here, ${ }^{36}$ the data can quite properly be regarded as an 18-year sampling of a continuing procession of cohorts which span the full biblical "three score years and ten". And, of course, the radiation is being delivered over this entire time span, at the very rates of interest, and compounded, so to speak, for effects in utero, on the young, on the general population, and on the aged. Admittedly, epidemiological data are susceptible to problems of over- and under-reporting, but these are hardly likely to be more severe than the parallel problems in small-group studies. Finally, the sheer mass of data permits far better cross-checking and, in many instances, provides insight into phenomena too minor to be observed in small-group studies but which may spark an idea or hypothesis in the mind of the investigator. ${ }^{47}$ Quite possibly it is this aspect which makes addicts of the adherents of epidemiology.

With this in mind, several curious observations appear in Table 1 . While each malignancy type at $r=0.003$ is within its respective statistical expectation, the consistent string of zero observed deaths, over populations that range from tens of thousands to. nearly ten million, is a bit unsettling. Admittedly very low incidences of certain malignancies are characteristic of ethnic and geographic groups throughout the world.9,26 But one is not usually prepared for such variations in a population supposedly so culturally uniform as that of the U. S. It appears that the U. S. population comprises groups whose range of cancer mortality is nearly as wide as that of the world at large, substantiating previously puzzling observations of wide disparities between major U. S. cities. $8,26,30$

Despite this heterogeneity, some socioeconomic bias exists in the U. S. data. Many of the 10 apocalyptic horsemen of Table 1, who refused to show significant groups below $r=0.3$, appear less formidable when viewed in the light of worldwide malignancy mortalities. In the first part of Table 2, we have presented the lowest national rates that we were able to find on inspection of the more readily available literature. Considering the usual urban-rural, male-female, ethnic-racial and socioeconomic diversities that one invariably finds in such national collections, one can anticipate finding sizeable groups at rates of zero or near-zero on closer study, even for these remaining $\mathrm{Mn}$ sites. Indeed, there appear to be large homogeneous groups below $r=0.3$ for all malignancies. $9,26,41,43$

Several features of Table 2 may be worth noting. First, the "secondary, 
Table 2.: Minimum National Rates for Ten Malign 三ncy Types

\begin{tabular}{|c|c|c|c|c|c|c|c|c|c|}
\hline \multirow[b]{2}{*}{ Mn Type } & \multicolumn{2}{|c|}{ AlI Azes } & \multicolumn{2}{|c|}{$\begin{array}{c}\text { U. S.: white, } \\
\text { male }\end{array}$} & \multicolumn{2}{|c|}{$\begin{array}{l}\text { U. S., white, } \\
\text { female }\end{array}$} & \multicolumn{3}{|c|}{ Early Adul thood } \\
\hline & r & Ref. & $\mathbf{r}$ & $d r \% d t$ & $r$ & $\mathrm{dr} / \mathrm{dt}$ & $\mathrm{R}$ & Age $\leqq$ & Ref. \\
\hline 151 & 0.6 & 43 & 15.6 & -0.69 & 8.0 & -0.35 & 0.0 & 35 & 27,37 \\
\hline 153 & 0.0 & 43 & 16.1 & +0.09 & 16.3 & $-0.0 \mathrm{~g}$ & 0.0 & 45. & 27,37 \\
\hline 155 & 0.0 & 43 & 3.0 & +0.03 & 3.7 & -0.05 & $0: 0$ & 40 & 27,37 \\
\hline 157 & 0.2 & 39 & 9.3 & +0.16 & 5.7 & +0.06 & 0.0 & 50 & 27,37 \\
\hline 163 & 0.0 & 37 & 19.1 & +0.96 & 3.6 & +0.12 & 0.0 & All & 37 \\
\hline 171 & 0.6 & 8 & - & - & 8.0 & -0.21 & 0.0 & 40 & 27,38 \\
\hline 174 & 0.5 & 37 & - & - & 4.8 & -0.26 & 0.0 & 50 & 37 \\
\hline 175 & 0.6 & 39 & - & - & 8.5 & +0.01 & 0.0 & 45 & 27 \\
\hline 177 & 0.0 & 43 & 17.6 & -0.09 & - & - & 0.0 & 45 & 27,37 \\
\hline "65". & $0.1-4.0$ & 8,37 & 11.6 & +0.01 & 9.7 & -0.17 & 0.0 & 40 & 27,37 \\
\hline
\end{tabular}


all other, and unspecified" categories 163, 174, and Burbank 65 characteristically constitute one of the major banes of the epidemiologist's existence $\left(e \cdot g \cdot{ }^{8}\right)$. One hardly anticipates data of much analytical value in such catchall categories. Even so, the fact that cancer is a reportable disease in the Scandanavian countries, 37 with their remarkably complete registries, eliminates 163 entirely and produces some very low rates for 174 and for some of the ICD types included in 65. It seems quite likely that more data of this quality would eliminate them completely. ${ }^{1,43}$. After all, they must, from their very nature, vanish to zero in the limiting case of perfect diagnoses.

Secondly, the very low rates observed help to dispel the enticing, if mildly parochial, notion that the remaining 7 types somehow constitute "common" malignancies, while the 46 eliminated via Table 1 are "rare". While these 7 do account for perhaps a third of total U. S. malignant mortality, 5 they hardly constitute important malignancies in other lands. Indeed, the only one of these to coincide with the BEIR list ${ }^{32}$ of important radiogenic malignancies, ICD 151, is dropping so linearly and rapidly in the U. S. that it bids fair to reach zero within the coming two decades. ${ }^{5,8}$ That something of the sort might transpire for several of the others is suggested by the data given in the second part of Table 2 , i.e., rates and values of $\mathrm{dr} / \mathrm{dt}$, the yearly change in age-adjusted mortality rate. 5

Some further test of the stature of these ten malignancy types may be made by considering generalizations (2) and (5). If these are indeed valid, a goodly fraction of the total radiogenic insult must have been received by age 10 and a significant number of radiogenic mortalities should have appeared by age 30 . However, this does not seem to be the case, as shown in the third part of Table 2, where $R$ is a specific age group rate. Here we have isolated those national rates for which we had age-specific data, and for which $R=0$ up to age 30 or beyond. Again, if these ten horsemen were truly riding to the beat of a radiogenic drum, they were certainly riding more slowly than predicted by the linear additive models so far proposed.

All in all, then, it appears that even the abandonment of polycarcinogenesis would do little for the additive model, especially in the long run, and this model will probably have to be abandoned in toto. 
ADDITIVE MODEL IN INFANCY

Infants irradiated in utero may well represent a special case. The heroic, case-by-case studies of Stewart 20,47 have shown not only a very marked effect of diagnostic radiography at very low doses, but a broad spectrum of Mn types as well, so that her results have often been used to buttress the generalization of pancarcinogenesis. ${ }^{2}, 3,13,31-33$ Stewart has reported a value of 572 malignant mortalities per million live births per rem of irradiation in utero, essentially all of them occurring before age $10.20,47$ Stewart also showed that sensitivity during the first trimester in utero was about thrice that during the last trimester. Following Sternglass 21 we budgeted the background by trimester at relative sensitivities of $3: 2: 1$. This yielded an age-specific rate, $R=1.11$, for in utero irradiation by the $130 \mathrm{millirem} / \mathrm{yr} \mathrm{U}$. S. natural background. We then added 40 millirem as a probable average in utero $\mathrm{X}$-irradiation ${ }^{4,20}$ at a relative sensitivity of 1 . The sum, $R=1.34$, was distributed among the 56 tumor types to give $R=0.024$ per type as an upper working level for test of hypothesis.

We screened U. S. experience as before, but with $R=0.024$ and for the 0-9 year groups only. All states were accumulated so that only the two sexes and two race groups were discriminated, in addition to the available age discrimination of $0-4$ and 5-9. Results are presented in Table 3 , with populations given in millions. With only 19 of the $56 \mathrm{Mn}$ types at $t$ less than 2, a hypothesis of pancarcinogenesis was untenable at the 0.024 leve1 of sensitivity. As before, we progressively lowered $R$ until, at $R \leqq 0.0018$, the pattern stabilized at the values given in the second column of Table 2 . Here, at an implied sensitivity about $8 \%$ of that found by Stewart for other malignancies, we were left with $34 \mathrm{Mn}$ sites at $\mathrm{r}=0$.

We turned again to the Monte Carlo method, and, for the mid-value $\mathrm{R}=0.0009$, obtained an expectation range of $11-42$, willı a liean of 27 , where only zero had been observed. 'lhus, the null hypothesis $(\mathrm{R}=0.0009)$ was also untenable. The results, rather, suggested that the actual sensitivity of the infant to background was of the order of $\leqq 0.15 \%$ of the sensitivity observed for diagnostic radiography, at least for these 34 types.

The remaining $22 \mathrm{Mn}$ sites are in excellent agreement with the spectrum found by Stewart for diagnostic radiation. Since we had no way of removing the radiographic component from these populations, these 22 remaining sites may well include radiogenic deaths due to radiography, precisely as per Stewart. For the natural background, they simply represent cases of "nu Les L".

The results are not consistent with a more selective model of additive carcinogenesis applicable only to these 22 sites. However, the cancers of early childhood form a rather special case of human malignancy.7, 8,10,20,25,44,47 They seem to be chiefly embryogenic in origin, have rates which are relatively constant over quite varied populations, and decrease in rate with increasing age (the converse of the situation above age 10 or so) $.5,7,8,10,20,25,26,44$ And, the 22 above only represent the most comnon malignancies in this age group. Thus, unlike the adult 10 horsemen above, it is improbable that zero rate groups will be found for more than a few of the 22, and the question of applicability of a partial additive model in this area is not likely to be answered by closer examination of worldwide experience along the lines used here. 
Table 3. Cancer Mortality and Expectations, 0-9 Year Group

\begin{tabular}{|c|c|c|c|c|c|c|c|c|}
\hline \multirow[b]{2}{*}{ ICD $\mathrm{Mn}$} & \multicolumn{4}{|c|}{$R=0.024$} & \multicolumn{4}{|c|}{$\mathrm{R}=0.0018$} \\
\hline & Exp. & obs. & $t$ & pop., Mil. & Exp. & obs. & $t$ & pop., Mil. \\
\hline 140 & 58 & 0 & 7.6 & 40 & 4.4 & 0 & 2.1 & 40 \\
\hline 141 & 58 & 1 & 7.5 & 40 & $4: 2$ & 0 & 2.0 & 39 \\
\hline 142 & 58 & 17 & 5.4 & 40 & 0.5 & 0 & 0.7 & 4.6 \\
\hline 143 & 58 & 6 & 6.8 & 40 & 0.7 & 0 & 0.8 & 6.2 \\
\hline 144 & 58 & 7 & 6.7 & 40 & 1.4 & 0 & 1.2 & 13 \\
\hline 145 & 58 & 4 & 7.1 & 40 & 1.6 & 0 & 1.3 & 15 \\
\hline 146 & 46 & 18 & 4.1 & 32 & 0.5 & 0 & 0.7 & 4.7 \\
\hline 147. & 58 & 0 & 7.6 & 40 & 4.4 & 0 & 2.1 & 40 \\
\hline 148 & 58 & 9 & 6.4 & 40 & 0.5 & 0 & 0.7 & 4.6 \\
\hline 150 & 58 & $i$ & 7.5 & 40 & 3.4 & 0 & 1.9 & 32 \\
\hline 151 & 58 & 13 & 5.9 & 40 & 0.3 & 0 & 0.6 & 3.0 \\
\hline 152 & 58 & 3 & 7.2 & 40 & 1.6 & 0 & 1.3 & 15 \\
\hline 153 & 56 & 27 & 3.8 & 39 & 0 & 0 & - & 0 \\
\hline 154 & 58 & 11 & 6.2 & 40 & 0.5 & 0 & 0.7 & 4.6 \\
\hline 155 & 4.3 & 4 & 0.1 & 3 & 0 & 0 & - & 0 \\
\hline 157 & 58 & 8 & 6.6 & 40 & 1.6 & 0 & 1.3 & 15 \\
\hline 158 & 16 & 11 & 1.3 & 11 & 0 & 0 & - & 0 \\
\hline 159 & 58 & 7 & 6.7 & 40 & 1.4 & 0 & 1.2 & 13 \\
\hline 160 & 58 & 20 & 5.0 & 40 & 0.5 & 0. & 0.7 & 4.7 \\
\hline 161 & 58 & 2 & 7.4 & 40 & 3.3 & 0 & 1.8 & 31 \\
\hline 162 & 58 & 20 & 5.0 & 40 & 0.7 & 0 & 0.8 & 6.2 \\
\hline 163 & 41 & 22 & 2.9 & 28 & 0 & 0 & - & 0 \\
\hline 164 & 54 & 23 & 4.2 & 37 & 0.2 & 0 & 0.4 & 1.5 \\
\hline 170 & 56 & 4 & 6.9 & 39 & 2.2 & 0 & 1.5 & 21 \\
\hline 171 & 28 & 10 & 3.4 & 20 & 0.2 & 0 & 0.4 & 1.5 \\
\hline 172 & 28 & 0 & 5.3 & 20 & 2.1 & 0 & 1.5 & \\
\hline 173 & 28 & 1 & 5.1 & 20 & 2.0 & 0 & 1.4 & 18 \\
\hline 174 & 28 & 8 & 3.8 & 20 & 0.2 & 0 & 0.4 & 1.5 \\
\hline 175 & 0 & 0 & - & 0 & 0 & 0 & - & 0 \\
\hline 176 & 16 & 2 & 3.5 & 11 & 0.3 & 0 & 0.6 & 3.1 \\
\hline 177 & 17 & 6 & 2.7 & 12 & 0.2 & 0 & 0.4 & 1.5 \\
\hline 178 & 15 & 13 & 0.5 & 10 & 0 & 0 & - & 0 \\
\hline 179 & 30 & 7 & 4.2 & 21 & 0.3 & 0 & 0.6 & 3.1 \\
\hline 180 & 0 & 0 & - & 0 & 0 & 0 & - & 0 \\
\hline 181 & 43 & 23 & 3.1 & 30 & 0.2 & 0 & 0.4 & 1.6 \\
\hline 190 & 58 & 17 & 5.4 & 40 & 0.2 & 0 & 0.4 & 1.5 \\
\hline 191 & 58 & 21 & 4.9 & 40 & 0.2 & 0 & 0.4 & 1.5 \\
\hline 192 & 0 & 0 & - & 0 & 0 & 0 & - & 0 \\
\hline 193 & 0 & 0 & - & 0 . & 0 & 0 & - & 0 \\
\hline 194 & 58 & 9 & 6.4 & 40 & 0.5 & 0 & 0.7 & 4.6 \\
\hline
\end{tabular}


Table 3. (Contd.)

\begin{tabular}{|c|c|c|c|c|c|c|c|c|c|}
\hline \multirow[b]{2}{*}{ ICD Mn } & \multicolumn{4}{|c|}{$\mathrm{R}=0.024$} & & \multicolumn{4}{|c|}{$R=0.0018$} \\
\hline & Exp. & obs. & $t$ & pop., Mil. & & Exp. & obs. & $t$ & pop., Mi1. \\
\hline 196 & 0 & 0 & - & 0 & & 0 . & 0 & - & 0 \\
\hline 197 & 0 & 0 & - & 0 & & 0 & 0 & - & 0 \\
\hline 200.0 & 2.3 & 2 & 0.2 & 1.6 & & 0 & 0 & - & .0 \\
\hline 200.1 & 0 & .0 & - & 0 & & 0 & 0 & - & 0 \\
\hline 200.2 & 2.1 & 2 & 0.1 & 1.5 & & 0 & 0 & - & 0 \\
\hline 201 & 29 & 17 & 2.2 & 20 & & 0 & 0 & - & 0 \\
\hline 202.0 & 58 & 0 & 7.6 & 40 & & 4.4 & 0 & 2.1 & 40 \\
\hline 202.1 & 0 & 0 & - & 0 & & 0 & 0 & - & 0 \\
\hline 20.5 & 58 & 0 & 7.6 & 40 & & $4: 4$ & 0 & 2.1 & 40 \\
\hline 203 & 58 & 5 & 7.0 & 40 & & 2.3 & 0 & 1.5 & 22 \\
\hline 204.0 & 0 & 0. & - & 0 & & 0 & 0 & - & 0 \\
\hline 204.1 & 2.1 & 2 & 0.1 & 1.5 & & 0 & 0 & - & 0 \\
\hline 204.2 & 0 & 0 & - & 0 & ${ }^{\circ}$ & 0 & 0 & - & 0 \\
\hline 204.3 & 0 & 0 & - & 0 & & 0 & 0 & - & 0 \\
\hline 204.4 & 0 & 0 & - & 0 & & 0 & 0 & - & 0 \\
\hline Al1 other & 0 & 0 & - & 0 & & 0 & 0 & - & 0 \\
\hline Sums & 1880 & 385 & - & - & & 51 & 0 & - & - \\
\hline
\end{tabular}


THE MULTPLICATIVE MODEL

Now, none of the foregoing bears on the multiplicative model except, possibly, to strengthen its position by removing a competitor. Indeed, the multiplicative model tends to predict much of what we saw. Relatively rare malignancies might be expected to show $r^{\prime}=0$, hence $r=0$ as we11. To be sure, it was a bit distressing that the anticipated mortalities below age 30 did not show up even though $r^{\prime}$ was clearly $<0$ over the remaining age. range. But then, this could be repaired by some changes in the values proposed for generalizations (2.), (3.) and (5.). Admittedly, radiation at low dose rates does seem to be remarkably ineffective as a complete pancarcinogen, or even as a complete carcinogen of any sort. But it could well be a pan-co-carcinogen, precisely as envisioned by the multiplicative model.

If this were the case, one would predict a fair increase of malignant mortality with increasing background, and this prediction has been made quite explicit by the model's authors, ${ }^{2,3}$ e. g., from $1 \%$ to $30 \%$ increase at $170 \mathrm{mrem} / \mathrm{yr}$, depending on various assumptions of latency, plateau, and doubling dose. $2,3,32$

With this in mind it was intriguing to note, in Table 1 , the resolute insistence on dwelling in regions of high background that seemed to characterize the low mortality groups. At $r=0.03$ and 0.003 on $1 y$ six groups were at the $170 \mathrm{mrem} / \mathrm{yr}$ national average, none were below the average, and at least 40 were above $180 \mathrm{mrem} / \mathrm{yr}$. At first we thought this might only be a secondary association with the well-known urban trend of $U$. S. cancer mortality. 14,26 Tests failed to substantiate this, however. 24 A white female resident of Dallas, for example (140 mrem/yr), simply seems to be about twice as likely to contract leukemia as her counterpart in Denver (290 mrem/yr). Since we doubted that anyone was prepared to ascribe oncolytic properties to the radiation background, we felt obliged to search for some other association. Surely there must be some sort of mortality increase with increasing background. $2,3,32$

However, plots of U. S. rates for white, malignant mortality ${ }^{5}$ against natural background for the 50 states showed, if anything, the reverse 54 e.g., Figure 1. Now, were it not for the insistence of the hypothesis ${ }^{2}, 3$ that there must be a correlation between malignant mortality and background, we would be inclined to dismiss Figure 1 as an example of simple noncorrelation. 46 However, of the 14 states above $140 \mathrm{mrem} / \mathrm{yr}, 12$ were very significantly $(P<0.01)$ below the $U$. S. average, one insignificantly lower, and only one slightly, but significantly, higher. The probability of this occurring by pure chance proved to be $<0.001$. Similar results were obtained with an independent estimate of natural backgrounds. 35

Several features of Figure 1 might be worth noting. First of al1, some states at common background had rates identical to the third significant figure, so that some of the single points actually represent pairs.

Secondly, no error bars are shown because the standard errors are less than the size of the points. The data base is, literally, enormous. Each point represents an average of about $10^{5}$ deaths, and a coefficient of variability, V, of about $0.3 \%$. Even the smallest states are represented 


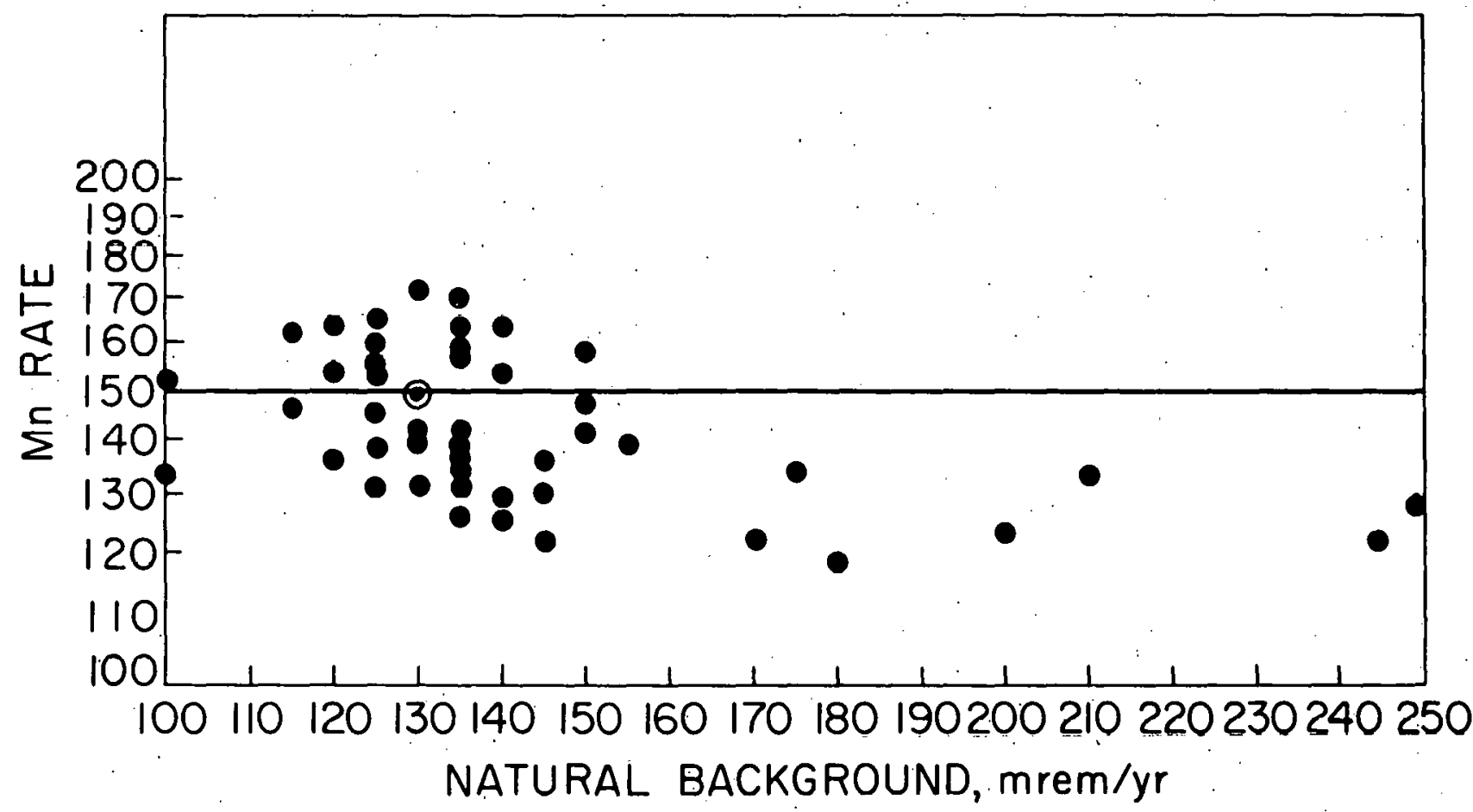

Fig. 1. Malignant Mortality Rates for the U. S. White Population, 1950-1967, by State and Natural Background. The horizontal line and open circle Indicate the rate and background for the U. S. as a whole. 
by about $10^{4}$ deaths, with $\mathrm{V} \simeq 1 \%$. With this sort of precision, it is evident that the vertical dispersion displayed is not "scatter", at least not in the usual sense. Rather, it reflects the operation of the genetic, cultural, socioeconomic and other environmental factors so well known in the epidemiology of malignancy. $7-10,14,20,25,26,39,41,43,44,46,47$

Finally, in addition to the seeming negative correlation of rate with background, ${ }^{49}$ the ten lowest states in the U. S. all lay at backgrounds of $\geqq 135 \mathrm{mrem} / \mathrm{yr}$. Thus, there seemed to be some real, if hidden, association between high backgrounds and low malignant mortalities. Although a similar and even more dramatic effect was noted in the non-white population, we confined ourselves to the white population because of its greater homogeneity, better statistics, the better availability of socioeconomic data, etc. 27,28

For purposes of further comparison, we discriminated three groups: A, the seven states of natural background above $165 \mathrm{mrem} / \mathrm{yr} ; \mathrm{B}$, the fourteen states of natural background above $140 \mathrm{mrem} / \mathrm{yr}$; $\mathrm{C}$, the fourteen states with the lowest backgrounds. These were compared with all $50 \mathrm{U}$. S. states, $24,27,28$ and some of the more pertinent results are summarized in Table 4.

We first analyzed the 50 states for each of the $56(\mathrm{Mn})$ types to see if the low mortalities of groups $A$ and $B$ could be due to particularly low rates for a few types. These two groups, however, proved to be lower in all categories than the $U$. S. average, and this premise had to be discarded. A summary is presented in lines 3-7 of Table 3. The rates for all categories, in fact, tended to decrease with increasing background.

Regressions against background and rate were then run for some 30 geographic, climatological and socioeconomic factors in an attempt to find some secondary association. 24 Some of these are summarized in Table 4. No associations were found beyond the obvious ones, i.e., high backgrounds 6,35 in the U. S. tend to be associated with higher altitudes ${ }^{23}$ because of the increased cosmic ray component. In the U. S., high altitude states are often located in the more arid regions and can be somewhat less urbanized than plains, or coastal states, e.g., group B. However, none of these associations was of the sort or strength that would be expected to lead to some marked difference in malignant mortality. $7,8,9,14,15,24,25,26,47$ In fact, the majority of the associations were in a direction inverse to that expected. Thus, the high background groups $A$ and $B$ had a generally lower or equal socioeconomic status (lines $10,11,12,13,15,16,17$ ) to the U. S. or group C, rather than the higher status that usually accompanies lower malignancy rates. $7,8,25,26$ The sole exception in this area was the median years of schooling (line 14). Further, A and B had lower Mn rates than U. S. or grnup C. despite a generally higher level of clieuical and radioactive pollution (lines 21-24) and also despite a slightly longer life expectancy, which would be expected to increase the mortality fraction due to malignancies. 8,26 The larger fraction of militarily acceptable males (line 18) only begs the question of why a rising level of healthy young males should be associated with a rising background.

Urbanization has been associated with increasing malignancy mortality, 14, 26 but these groups are, at best, mixed in this respect (line 9). In any case, state-by-state comparisons showed little strength or consistency 26 in this 
Table 4. U. S. Low and High Background White Populations, 1950-1967

\begin{tabular}{|c|c|c|c|c|c|}
\hline No. & Characteristic & A & B & U. S. & $\mathrm{C}$ \\
\hline 1 & Natural background, mrem/yr & 210 & 170 & 130 & 118 \\
\hline 2 & White population, thousands & 5735 & 16,897 & 158,051 & 59,683 \\
\hline 3 & $r$, Mn $140-159$ & 42.9 & 45.6 & 52.4 & 50.3 \\
\hline 4 & $r, \operatorname{Mn} 160-164$ & 15.8 & 16.9 & 22.3 & 23.4 \\
\hline 5 & $r$, Mn $170-181$ & 36.8 & 38.2 & 41.5 & 40.1 \\
\hline 6 & $\therefore$, Mir 190-205 & 30.8 & 31.5 & 33.3 & 33.0 \\
\hline 7 & r, $\Lambda 11$ malignancies & $1 \% .3$ & 1.32 .2 & 149.5 & 146.8 \\
\hline 8 & Residence altitude, ft & 4510 & 2650 & 900 & 730 \\
\hline 9 & Urbanization, \% & 63 & 57 & 69 & 74 \\
\hline 10 & Per capita personal income, $\$$ & 2021 & 1922 & 2215 & 2255 \\
\hline 11 & Median family income, $\$$ & 5600 & 5400 & 5660 & 5650 \\
\hline 12 & Physicians/1000 population & 1.27 & 1.25 & 1.49 & 1.49 \\
\hline 13 & Hospital beds/1000 population & 8.24 & 8.82 & 9.49 & 8.76 \\
\hline 14 & Median years of school completed & 11.8 & 11.7 & 10.9 & 10.8 \\
\hline 15 & Poor diet households, \% & 16.5 & 21.2 & 19.1 & 19.1 \\
\hline 16 & Population on Federal Food Assist, \% & 2.6 & 3.2 & 3.2 & 2.5 \\
\hline 17 & Unemplơywient, \% & 4.3 & 3.9 & 3.9 & 3,3 \\
\hline 18 & $\begin{array}{l}\text { Accepted, Military Selective } \\
\text { Service }\end{array}$ & 65 & 63 & 56 & 53 \\
\hline 19 & Life expectancy, male & 67.7 & 67.7 & 67.6 & 67.5 \\
\hline 20 & Life expectancy, female & 74.5 & 74.7 & 74.2 & 74.3 \\
\hline 21 & Urban air, particulates, $\mu \mathrm{gm} / \mathrm{m}^{3}$ & 129 & 119 & 115 & 116 \\
\hline 22 & Urban air, benzerie soluble, $\mu \mathrm{gm} / \mathrm{m}^{3}$ & 10.1 & 9.3 & 9.5 & 9.6 \\
\hline 23 & Urban air, radioactivity, $\mathrm{pCi} / \mathrm{m}^{3}$ & 8.5 & 7.7 & 6.8 & 6.3 \\
\hline 24 & Urban air, beta, $\mathrm{pCi} / \mathrm{m}^{3}$ & 5.5 & 5.2 & 4.4 & 4.2 \\
\hline
\end{tabular}


Table 4. (Contd.)

\begin{tabular}{llcccc}
\hline No. Characteristic & \multicolumn{1}{c}{ A } & B & U. S. & C \\
\hline 25 & r, Mn 140-205, age 0-9 & 8.11 & 8.31 & 8.54 & 8.31 \\
26 & r, Mn 140-205, age 10-19 & 6.80 & 6.61 & 6.82 & 6.72 \\
27 & r, Mn 140-205, age 20-29 & 10.46 & 10.73 & 11.09 & 11.19 \\
28 & r, Mn 140-205, age 30-39 & 27.61 & 28.39 & 31.45 & 32.27 \\
29 & Mortality rate, al1 causes & 892.0 & 893.2 & 928.5 & 903.9 \\
30 & U. S.-group, al1 causes & 36.5 & 35.2 & - & 24.6 \\
31 & U. S.-group, malignancy & 23.2 & 17.3 & - & 2.7 \\
32 & r, Stomach, 151 & 11.7 & 11.6 & 11.8 & 11.0 \\
33 & r, All G. I., 150-159 & 40.7 & 43.0 & 49.0 & 46.7 \\
34 & r, Lung, 163-164 & 14.5 & 15.5 & 20.4 & 21.5 \\
35 & r, Breast, female, 170 & 21.5 & 22.6 & 25.3 & 24.4 \\
36 & r, Thyroid, 194 & 0.055 & 0.054 & 0.057 & 0.054 \\
37 & r, Bone, 196 & 0.92 & 1.03 & 1.12 & 1.07 \\
38 & r, Leukemia, 204 & 7.03 & 7.23 & 7.13 & 6.91 \\
\hline
\end{tabular}


area. ${ }^{24}$ In addition, comparisons of 16 Standard Metropolitan Statistical areas in groups $\mathrm{A}, \mathrm{B}$ and $\mathrm{C}$ gave the same results as those of the groups in toto, i.e., urban areas in $A$ or $B$ showed much lower rates than those in $C$, even for areas of common socioeconomic and ethnic factors. ${ }^{24}$ In short, if any associations existed at all, they were in such a direction as to lead to increased rates for $A$ and $B$. In the face of all this it was difficult to see how the multiplicative model could be maintained or, in fact, any mode 1 which predicted an increase of malignant mortality with increasing background.

Then, too, the greatly increased sensitivity of the young should lead to a marked increase in malignant mortality. 2,3 Even if the low spontaneous rates of the very young should somehow mask this, combined with the predominantly embryogenic character of childhood malignancy, an increase should certainly be evident by middle age. In fact, the reverse is the case (1ines 25-28). The observed rates among the young of groups $A$ and $B$ are decreased relative to those of $\mathrm{U}$. S. and group $\mathrm{C}$, and in much the same ratio as the total malignant mortalities. Even more than the total observations, this left either the additive or the multiplicative model without the attributes of a viable epidemiologic mode1. ${ }^{28}$.

Giving consideration to the fact that radiation cannot be the only carcinogen, that we have far from exhausted the existing low-mortality groups at high backgrounds, even for the U. S., and that we have probably understated the actual exposures of the population by ignoring full medical and dental exposures, weapons, fallout, and regions of high local background, it appears that the actual carcinogenic effects of low-level, low dose-rate radiation are very much less than those predicted from higher level and rate studies, $1-3,13,15,20-22,26,31,34,40$ if, in fact, there are any at all. In short, extrapolation from high-rate, small-sample studies predicts a marked increment in malignant mortality rate due to the natural radiation background. Observation of the actual populations at risk shows not only no increment, but an actual decrement.

While identification of the factors at work remains a fascinating exercise for the future, it is not necessary to await such identification to conclude that low-level, low-rate, low LET radiation constitutes a negligible environmental carcinogen. If it. is permissible to extrapolate data from Japanese bomb victims, British spondylitics, uranium miners, etc. to the U. S. population at large, then it is certainly far more permissible to extrapolate portions of the U. S. population to itself. This done, the present evidence is quite incompatible with an increase of malignant mortality with increasing background. For a model of background carcinogenesis to remain viable it will be necessary not only to identify reversing factors, but to quantify them with sufficient precision to be certain that they are, indeed, significant factors, and not merely possibilities without quantitative pertinence.

Indeed we claim no novelty for the tests applied above. The existence of geographically contiguous populations of malignant mortalities low enough to place an upper bound on the involvement of uniformly distributed carninogens has been previously noted,26,29,41,43 as has the low malignant incidence in at least one high-background city. ${ }^{30}$ All that we have done is to quantify these to the point where simple statistical causes can be ruled out. 
Certain possibilities, for example, were ruled out by the nature of the observed mortality pattern. Thus, if the decedent populations of groups A or $B$ above were to contain significantly large numbers of immigrants from other parts of the U.S., (i.e., the decedents had not been exposed to the high backgrounds until late in life), one would have expected the rates in groups $A$ and $B$ to be higher than those of the remaining states. This because the $\mathrm{Mn}$ rates of the remaining states are much higher than those of $A$ or $B$, e.g., 150.4 for the U. S.-minus-A, and 151.6 for the U. S.-minus-B. Instead, the reverse was true. Accordingly, if short-term residents are a factor, the true rates for the long-term residents must be even lower than those given in Table 4.

In this context, too, the problem of competing risks arises. 2,46 Thus, are the populations of groups $A$ and $B$ dying of some other cause, so that their members are removed before malignancy can become manifest? Fortunately, the data were at hand to answer this. The age-adjusted mortality rates for all causes could easily be computed, and these are presented in Table 4 (1ine 29), along with the decrements of each population, relative to the U. S., for all causes (line 30), and for malignancy alone (line 31). AlI three of these groups are slightly lower than the U. S. in total mortality rate, and by about the same amount. The malignant decrement, however, decreases rapidly with decreasing background. Indeed, in the very highest background group, the malignancy decrement is very nearly equal to the total decrement. This is just the reverse of a case of competing risks, at least in the sense given above.

Again the possibility existed that the residents of group A or B were characterized by much lower radiographic exposures than those of the U. S. This, however, fell of its own weight, since it would have required an excess of over $300 \mathrm{mrem} / \mathrm{yr}$ in the rest of the U. S. to account for the difference in group A, and another $80 \mathrm{mrem} / \mathrm{yr}$ to account for the expected increase of A due to its high background. ${ }^{2}, 3$ Such values are hardly. credible in view of what is known for U. S. radiographic exposures: $4,12,16,32$

In addition, a multiplicative model predicts a radiation independent rate, $r^{\prime}$, given by $r^{\prime}=r / m$. Here $r$ is the observed rate, and $m=(D / D D)+1$, where $D$ is the total background dose, and DD the doubling dose. ${ }^{2,3}$ If this explession truly represented the case one would expect the dispersion of the corrected rates, $r^{\prime}$, to decrease relative to the dispersion for $r .{ }^{42}$ This is the case for such factors as urbanization in total malignant mortality, solar exposure in skin cancer mortality for whites, etc., 24 so that it should easily be the case for a factor which accounts for $1 \%$ to $30 \%$ of the total U. S. rate.

Following previous authors ${ }^{2}, 3$ we took $\mathrm{DD}=50$ rem for the general population and $D$ as equal to 30 times the total annual background for the State. ${ }^{6}$ The 1950-1967 rates, r, were from Burbank ${ }^{5}$ as before. For $r$ the coefficients of variability, $V$, for white males, nonwhite males, white females and nonwhite females were $11.44 \%, 21.52 \%, 8.98 \%$ and $12.26 \%, 45$ respectively. After correction to $r^{\prime}$, as above, these values increased to $12.23 \%, 22.08 \%, 9.55 \%$, and $12.25 \%, 45$ respectively. Regardless of which of the suggested values $2,3,32$ we used for $\mathrm{D}$ or $\mathrm{DD}, \mathrm{V}$ invariably increased, i.e., the results were always the opposite of what would have been expected if the model represented a real factor in U. S. malignant mortality. Furthermore, this increase in $\mathrm{V}$ was 
found to hold for essentially all U. S. malignancies, even for leukemia, the classic of radiogenic malignancies. Thus, we seemed to be left without statistical support. for a multiplicative model, either for all malignancies (pancarcinogenesis), or even for specific ones. 
OTHER MODELS

Most of the foregoing would apply with equal force to any model of radiation carcinogenis that predicted increased mortality below the $300 \mathrm{mrem} / \mathrm{y} \cdot \mathrm{r}$. or so that characterizes the highest U. S. populations. However, two such models have been proposed that deserve explicit mention, if only because their tenets are so reasonable. 22,34

For many forms of cancer the spontaneous incidence rises exponentially. with age, i.e., as $\exp (a t)$, where $a$ is a constant and $t$ is time. It is often postulated that the effect of radiation exposure might be to shift the exponential so that incidence now depends on $\exp [a(t+b)]$, where $b$ is $a$ variable depending on radiation dose. This can be understood as either a multiplying effect of radiation or as an aging effect, depending on which axis is shifted to superimpose results from irradiated and unirradiated populations. In either case, though, this predicts a general increase in. mortality with. increasing background, as well as prominent effects occurring at the earlier ages. ${ }^{22}$ Neither of these predictions is compatible with the results presented in the previous section.

A yet more recent model $1^{34}$ addresses the question of differences in. individual sensitivity. Thus, the most sensitive subgroups respond at the lowest doses, so as to cause a steeper-than-linear slope in the low-dose portion of the dose-effect. However, this model predicts even higher mortalities at very low doses than the linear models treated in the previous sections, so that it, too, is incompatible with their results.

Any number of equally reasonable models could certainly be erected but, in the last analysis, reasonableness is not the ultimate criterion of a model. It's not that the models are unreasonable, but that Nature seems to be!

We11, reasonable or not, was she "straight.", i.e., linear? We further. examined rates for the 7 malignancies that have provided most of the date for present extrapolations. ${ }^{32}$ These are arraigned in Table 4, lines 32-38 and, again, the verdict seems to be "not guilty".

For thyroid carcinoma the mortality fraction is so low that incidence is a more useful measure than mortality. ${ }^{32}$ The most recent estimates have given 3400-6800 new cases per year, at $170 \mathrm{mrem} / \mathrm{yr}$, over the U. S. population, 32 i.e., a radiogenic rate of about 2.6 . Against this may be compared Scandinavian ${ }^{37}$ and U. S. ${ }^{8}$.total rates of $0.6-1.3$, with several metropolitan populations at 0.0 .8

Thus, Nature has been anything but "straight" with us, and Iinearity seems to be, if not deceased, at least moribund. 
FUTURE MODELS

Now, statistical analysis can certainly demolish a hypothesis, and this is part of the science of epidemiology. But it can hardly propose one, nor yet can it establish causality. ${ }^{46}$ These latter exercises are, really, the "art". of epidemiology and, in the last analysis, its ultimate justification. Hence, we would feel derelict if we did not hazard some opinion as to the direction future models might take.

Examination of generalizations (1.) through (5.) revealed nothing unreasonable and little that was not consonant with what is known. The toxicological dictum that "all men are brothers" has well stood the test of time. And, if radiation at high dose-rates is not pancarcinogenic, 1 t is, at least, polycarcinogenic. The remaining generalizations are primarily numerical, and could be easily modified if need arose.

Perhaps the simplest accommodation would be to abandon the assumption of simple linearity and to substitute some function more dependent on dose rate and dose 1evel, as suggested by parts of the BEIR Report. ${ }^{2}$ Certainly the "dose-rate effect" has been known for many years 15 and is, in fact, the basis of the fractionation procedures common in radiotherapy, as we 11 as the low-leve1, whole-body irradiation methods being attempted for the therapy of some malignancies.

Furthermore, dose rate factors of the order of 5-15 have been reported for large populations of mice irradiated for 1 ife at modest rates, ${ }^{16}$ and a very strong dose-rate effect has been reported for mutagenes is in mice. 48 A nonlinear model for such diminuition of effect, and even for its reversal, 50 has recently been erected and partially tested.17 Since linearity has always been an inference rather than an observation, 13,3253 and since extrapolation over many orders of magnitude ${ }^{51}$ has always been a dubious procedure at best, 52 this path of hypothesis rejuvenation appears the most attractive a priomi. No matter which hypotheses are advanced, however, we hope that the availability of epidemiological techniques and data will come as an "aid and comfort" to the beleaguered radiobiologist in his search for reliable estimates of the effects of radiation on human populations. 


\section{CONCLUSIONS}

In an attempt to uncover some secondary association between rising background and falling malignancy rate, regressions were run for additional factors beyond those shown in Table 4. These are summarized in Table 5 . Again, no meaningful associations were found beyond the obvious ones, i.e., high backgrounds tend to be associated with high altitudes because of the increased cosmic ray component. However, in the U..S., high terrestrial backgrounds accompany high altitudes because of the particular geology of mountainous regions. $6,23,35$ Thus, as seen on lines 1 and 2 , both components decrease going from group A to group C. Thus, as one would expect, groups A and B tended to be drier, cooler, higher, sunnier, (lines 3-7) than group $C$, and to require more domestic heating (line 8). (The latter may account for the higher air pollution levels noted in lines 21 and 22 of Table $4_{.}$) We know of no observation, or even hypotheses, $7-10,25,26,41,43,44,46$ that would causally link these factors with decreased malignancy. Thus, we were forced to conclude that their association with increased backgrounds was an accident of altitude and geology, and not significant in the observation of decreasing malignant mortality rates with increasing background.

A number of other regressions of possible socioeconomic indicators were also run and are presented in Table 5. However, none of these provided any secondary associations that might be expected to lead to decreased malignancy. At best, the groups were mixed, and showed no correlation. At worst, the correlations detected were in a direction that should have led to increased malignancy in groups $A$ and/or $B$.

Although the dose estimates used 6,35 are the result of careful, independent and prolonged studies, and certainly the best values available, we reexamined them for the possibility that the results which we obtained were an artifact of dose estimates. This did not appear to be the case. Groups A and C, especially, consisted of states where simple altitude. and geological considerations, coupled with repeated measurements over the years, have shown these states to be quite disparate in background. The majority of these states, in fact, have been among the classical examples of high and 1 nw harkground states for decades. In addition, study of the sources cited suggested the true backgrounds in groups $A$ and $B$ were very probably higher than those used in that houses were most of ten made of stone or concrete of high radioactivity, indoor air had often been shown to be very high in radon, and the population spent a larger fraction of time indoors because of the relatively inclement weather compared to the rest of the U. S. or to group C. Thus, if anything, the background of groups $A$ and $B$ had been underestimated relative to the $U$. $S$. or to group C.

The current models of radiation carcinogenesis have all derived their data from smal1, selected, populations, at high dose rates and generally at high dose levels. They have assumed monotonic extrapolation to zero dose, even though this assumption has always been without observational basis.13,32 They have also assumed such extrapolation can be made without consideration of dose rate, an assumption not on 1.y wi thout observational basis, but one contradicted by a large body of radiological and toxicological 
Table 5. Characteristics of U. S. White Populations at Low and High Backgrounds

\begin{tabular}{|c|c|c|c|c|}
\hline No. & Characteristic & A & B & $\mathrm{C}$ \\
\hline 1 & Cosmic ray dose, mrem/yr & 105 & 72 & 42 \\
\hline 2 & Terrestrial dose, mrem/yr & 80 & 72 & 51 \\
\hline 3 & Mean altitude, feet & 5400 & 2900 & 1300 \\
\hline 4 & Annual mean temp., ${ }^{\circ} \mathrm{F}$ & 50 & 51 & 59 \\
\hline 5 & Annual precip., inches & 14. & 25 & 36 \\
\hline 6 & Days/yr with prectp. & 86 & 97 & 99 \\
\hline 7 & $\%$ of possible sunshine & 69 & 65 & 63 \\
\hline 8 & Annua1 degree-days $\left(65^{\circ} \mathrm{F}\right)$ & 6300 & 6100 & 3550 \\
\hline 9 & Murder, per $10^{5}$ pop.* & 3.9 & 4.0 & 4.9 \\
\hline 10 & Rape, per $10^{5}$ pop. & 9.9 & 7.6 & 9.7 \\
\hline 11 & Robbery; per $10^{5}$ pop. & 39.8 & 30.2 & 49.2 \\
\hline 12 & Agg. assault, per $10^{5}$ pop. & 37.2 & 64.9 & 82.0 \\
\hline 13 & Burglary, per $10^{5}$ pop. & 476 & $399^{\circ}$ & 574 \\
\hline 14 & Larceny, per $10^{5}$ pop. & 331 & 260 & 297 \\
\hline 15 & Auto theft, per $10^{5}$ pop. & 218 & 167 & 209. \\
\hline 16 & Lawyers, per $10^{5}$ pop. & $140^{\circ}$ & 125 & 133 \\
\hline 17 & Marriages, per $10^{5}$ pop. & 993 & 1114 & 783 \\
\hline 10 & Divorceo, per $10^{\mathrm{j}}$ pop. & 276 & 242 & 237 \\
\hline 19 & Urban births, per $10^{5}$ pop. & 1563 & 1381 & 1423 \\
\hline 20 & Rural births, per $10^{5}$ pop. & 1025 & 1082 & 818 \\
\hline
\end{tabular}

*Lines 9-18 are for total populations. 
data. 15-17,24 On these bases predictions have been made of significant increments in malignant mortality rates due to the radiation background. Observation of actual populations at risk shows not only no increment but an actual decrement, and these predictions are left quite without observational support. Thus, it appears that one or both of the above assumptions is invalid and that background radiation does not constitute an environmental carcinogen of significance. By the same token, the radiation added by nuclear power plants cannot be a carcinogenic hazard either, since it has the same radiobiological character as the current background, but is . much lower in both dose level and rate. 


\section{REFERENCES AND NOTES}

1. Pauling, L., No More War, Dodd-Mead, N.'Y. C., (1958).

2. Gofman, J. W., and A. R. Tamplin, Poisoned Power, Rodale Press, Emmaus, Pennsylvania, (1971), Sixth Berkeley Symposium on Mathematical Statistics and Probability, Univ. of Claifornia, July 20, 1971, 6:235, and Gofman, J. W., et al., Symposium on Fundamental Cancer Research, Univ. of Texas, March 3, 1971 .

3. Tamplin, A. R., and J. W. Gofman, Population Control Through Nuclear Pollution, Nelson-Ha1l, Chicago, (1971).

4. U. S. Public Health Service, Pub1. No. 2001, Population Dose from X-rays, Wash., D. Ci, (1969).

5. Burbank, F., Patterns in Cancer Mortality in the U. S., National Cancer Institute, Monograph 33, Washington, D. ('., (19/i).

6. Minx, R. P., B. Schlelen, A. W. Klement, and C. R. Miller, Nuclear News, 15:47, (1972), and USEPA Report ORP/CSD-72-1, (1972).

7. Steiner, P., Cancer, Race, and Geography, Williams and Wilkins, Baltimore, (1954).

8. Cowdry, E. V., Etiology of Cancer in Man, Appleton-Century-Crofts, N. Y. C., (1968).

9. Higginson, J., Practitioner, 198:621, (1967), Annual Reports, International Cancer Research Agency, World Health Organization, Geneva, (1968-1970), Med. Hyg., 25:774 (1967), and S. Afr. J. Med. Sci., 31: 21 (1966).

10. Ackerman, L., and J. DelRegato, Cancer, Mosby, St. Loui.s, (1970).

11. Brownlee, K. A., Statistical Theory and Methodology in Science and Engineering, Wiley, N. Y. C., (1960).

12. Gitlin, J. N. and P. S. Lawrence, Population Exposure to X-rays, U. S. Public Health Service, No. 1519, Washington, D. C., (1964).

13. Int. Comm. on Radiol. Prot., Radiosensitivity and Spatial Distribution of Dose, Pub1. No. 14, Pergamon Press, (1969).

14. MacDonald, E. J., D. G. Wellington, and P. F. Wolf, Cancer, 20:617, (1967).

15. Upton, A. C., Meth. Canc. Res., 4:53, (1968) and Ann. Rev. Nuc1. Sci. 18:495, (1968), Rad. Res. 41:467, (1970).

16. Grahn, D. F., R. J. M. Fry, and R. A. Lea, Life Sciences and Space Research, 10:267, (1971). 
17. Sacher, G. A., S. A. Tyler, and E. Trucco, Argonne National Laboratory Report, ANL-7970, p. 60, (1971), and Biological Aspects of Aging, N. W. Schock, Ed., Columbia Univ. Press, p. 244, (1962).

18. Kenda11, M. G., and A. Stuart, The Advanced Theory of Statistics, Chas. Griffin Co., London, (1958).

19. Shreider, Yu. A., (Ed.) The Monte Carlo Method - A Method of Statistical Trials, Pergamon Press, Oxford, (1966).

20. Stewart, A., Adv. Canc. Res. 14:359 (1971).

21. Sternglass, E., Hanford Symposium on Radiation Carcinogenesis, 11 May 1972, Richland, Washington, in press, and Sixth Berkeley Symposium on: Mathematical Statistics $6: 145$, Univ. of Calif. Press; Berkeley, (1972).

22. Mole, R. H., Health Physics, 20:485 (1971).

23. Grahn, D., and J. Kratchman, Amer. J1. Human Genetics, 15:329. (196.3).

24. Frigerio, N. A., K. Eckerman, and R. Stowe, to be published.

25. Willis, R. A., Pathology of Tumors, C. V. Mosby Co., St. Louis, (1953).

26. MacMahon, B., and T. F. Pugh, Epidemiology; Little-Brown, Boston, (1967), and J1. Nat. Canc. Inst. 28:1173 (1962).

27. Vital Statistics of the U. S., U. S. Dept. of Commerce, Washington, D. C., (1950-1968).

28. Statistical Abstracts of the U. S., U. S. Dept. of Commerce, Washington, D. C., (1950-1972).

29. Bond, V. P., USAEC Report TID-25857, pp. 92-103 (1972).

30. Libby, W. F., The Nature of Radioactive Fallout and Its Effects on Man, Washington, D. C., U. S. 85th Congress, pp. 1517 and 1523 (1957).

31. Argonne National Laboratory, Conference on the Estimation of Low-Level Radiation Effects in Human Populations, Report ANL-7811, Dec. 1970.

32. Advisory Comm. on the Biological Effects of Ionizing Radiation, The Effects on Populations of Exposure to Low Levels of Ionizing Radiation,. Nat'1. Acad. Sci., Washington, D. C. (1972). (The BEIR Report)

33. Hutchison, G. B., Radiology, 105:645 (1972).

34. Baum, J. W., Population Heterogeneity Hypothesis on Radiation Induced Cancer, Brookhaven National Laboratory Report.BNL-17267, (1972).

35. Oakley, D. T., Natural Radiation Exposure in the U. S., USEPA Report ORP/SID-72/1, (1972). 
36. We recently began examination of the data available for 1930-1950, thinking that these might differ from the post-1950 "fallout period." However, our preliminary results only confirm the 1950-1967 patterns presented above.

37. Ringertz, N., Acta Path. Micr. Scand. Supp1. \#224, 95 pp., (1971), and previous reports in this series. Incidences are given, rather than mortalities.

38. Steinitz, R., and C. Costin, Israe1 J. Med. Sci. 7:1405 (1971).

39:. Segi, M., M. Hurihara, and T. Matsuyama, Cancer Mortality in Japan (1899-1962), Dept. of Public Health, Tohoku University, Sendai, Japan, (1965).

40. Sternglass. E., Low Level Radiation, Ballant1ne Books, N. Y. C., (1972).

41. Stefansson, V., Cancer, Hill and Wang, i. Y. C. (1960).

42. This is analogous to the spectrum stripping process common in physics. 11,18 In this case the radiogenic rate is the "known line." The groups tested passed $x^{2}$ tests for normal distributions, with white females actually passing tests for a Poisson.

43. Dunham, L. J., and J. C. Bailar, J. Nat. Canc. Inst. 43:155 (1968).

44. Peller, S., Cancer in Man, Int. Univ: Press, N. Y. C. (1952).

45. The corresponding values of variance/mean for $r$ were: $337 / 160,1439 / 176$, $124 / 124,316 / 145$. For $r^{\prime}: 315 / 145,1241 / 159,114 / 112,257 / 130$. Some skewness and kurtosis was found but 1t, too, was in the direction opposite to that predicted by the mode1, probably reflecting the negative correlaliums of Fig. 1 and Table 4 .

46. Neyman, J., Sixth Berkeley Symposium on Mathematical Statistics, $\underline{6}: 561$, 575 Univ. of Calif. Press, Berkeley, (1972).

47. Stewart, A., An Epidemiologist Takes a Look at Radiation Risks, USDHEW Report BRH/DBE-73-2, Rockville, Md., 108 pp. (1973).

48. Russel1, W. L., Pediatrics, 41:223 (1968).

49. As Neyman has recently pointed out, 46 a negative correlation on rates need not be an indication of negative co-carcirogenesis, in accord with the "organic correlation" analyses of Pearson and Galton.

50. Shades of Arndt-Schulz:

51. Between diagnostic radiography, and the natural background, the doserate varies by about $10^{9}$.

52. Stewart, A., New Scientist, 1969, p. 181 (24 July, 1969). 
53. Brues, A. M., Arch. Env. Health 22:690 (1971).

54. Similar correlations have been noted in studies of infant mortality around nuclear reactors, e.g. A. Hull and F. J. Shore, Brookhaven National Laboratory Report BNL-16613 (1972).

55. In this we are greatly indebted to Drs. Gofman, Bond, Brues, Sacher, Tyler, Hu11, Baum, Gustafson, and Grahn, and to the anonymous reviewers identified only as HP, 35, and 195, for their comments and criticisms. Benedicomus te. 